\title{
lodine status and characteristics of Korean adole- scents and their parents based on urinary iodine concentration: a nationwide cross-sectional study
}

\author{
Yun Chang Choi, MD, \\ Ji In Cheong, MD, \\ Hee Won Chueh, MD, PhD, \\ Jae-Ho Yoo, MD, PhD
}

Department of Pediatrics, Dong-A University College of Medicine, Busan, Korea
Received: 16 August, 2018

Revised: 27 September, 2018

Accepted: 12 November, 2018

Address for correspondence: Jae-Ho Yoo, MD, PhD

Department of Pediatrics, Dong-A University Hospital, Dong-A University College of Medicine, 26 Daesingongwon-ro, Seo-gu, Busan 49201, Korea

Tel: +82-51-240-5124

Fax: +82-51-242-2765

E-mail: pedendo@dau.ac.kr

https://orcid.org/0000-0003-3065944X
Purpose: lodine is a major component of thyroid hormones. Both deficiency and excess of iodine are major risk factors for thyroid disease, making it important to accurately assess iodine level in the human body. Urinary iodine concentration (UIC) is a commonly used measure of iodine status. However, there is little research on iodine status and related characteristics in Korean adolescents.

Methods: Using data from the sixth Korea National Health and Nutrition Examination Survey (KNHANES VI) for the years 2013-2015, we analyzed UIC and thyroid function test results in adolescents aged 10-18 years and their parents. We also investigated the influence of socioeconomic factors and family history of thyroid disease on iodine status.

Results: Mean UIC in Korean adolescents was $963.5 \pm 55.7 \mu \mathrm{g} / \mathrm{L}$. Among evaluated subjects, $6.6 \% \pm 1.0 \%, 29.8 \% \pm 1.7 \%$, and $63.9 \% \pm 1.9 \%$ had low $(\mathrm{UIC}<100 \mu \mathrm{g} / \mathrm{L})$, adequate (UIC: $100-299.9 \mu \mathrm{g} / \mathrm{L}$ ), and excess (UIC $\geq 300 \mu \mathrm{g} / \mathrm{L}$ ) iodine concentrations, respectively. Based on regional trends, the incidence of iodine deficiency exceeded $10 \%$ in several regions, even though there was a dominance of regions with excess iodine. Parental UIC, female sex, average monthly income, and expenditure were all found to affect the iodine status of Korean adolescents.

Conclusion: Although regional differences exist, the iodine status in Korean adolescents is mainly affected by the eating habits of their families and socioeconomic factors. Therefore, monitoring of iodine status is necessary in this population.

Keywords: lodine, Korea, Adolescents, Parents, Thyroid hormones

\section{Introduction}

Thyroid hormones are involved in cellular metabolic processes such as bone growth, lipid metabolism, and enzymatic activity of hepatocytes. They also play an important role in brain development in infants and young children and growth during adolescence and puberty. ${ }^{1)}$

Iodine is a major nutritional component of thyroid hormones and is supplied by various food sources. ${ }^{2}$ Thyroid hormones are synthesized by organification of iodide. Over $90 \%$ of ingested iodine is absorbed by the stomach and duodenum and ionized to iodide, which is then transported into thyrocytes by sodium/iodine symporters. Next, the iodide is transferred back to the iodine pool within the plasma by deiodinase. The half-life of iodine within the plasma is about 10 hours, which is shorter in the case of iodine deficiency. ${ }^{3)}$

Exposure of up to $1,100 \mu \mathrm{g} /$ day of iodine is generally considered safe for healthy adults. ${ }^{4)}$ However, exposure to excess iodine in a short period can inhibit the synthesis of thyroid hormones through the acute Wolff-Chaikoff effect. ${ }^{5}$ Additionally, consistent exposure to excess iodine can increase the risk of thyroid dysfunction. ${ }^{6}$ Therefore, it is important to maintain appropriate iodine level within the body for good thyroid health. 
An insufficient level of iodine is recognized as a major health issue. The World Health Organization (WHO) and other international organizations have recommended consistent monitoring of iodine status among people. Total goiter rate and thyroid ultrasound can be used to monitor iodine concentration, ${ }^{7)}$ but urinary iodine concentration (UIC) has been the measure most commonly used to assess body iodine status following the introduction of iodized salt programs across many countries in the 1990s. ${ }^{8)}$

Over $90 \%$ of ingested iodine is excreted in the urine within 24-48 hours, ${ }^{9,10)}$ making UIC an excellent marker of iodine status. ${ }^{8)}$ The WHO recommends using the UIC of spot urine as a marker for assessing body iodine status. The median UIC value is especially useful for assessing the iodine status of school-age children. ${ }^{11)}$ A study by Ascoli conducted in 186 regions across Central America before ionized salts were supplied in 1970 reported that UIC values less than $100 \mu \mathrm{g} / \mathrm{L}$ were indicative of iodine deficiency. ${ }^{8)}$ To eradicate iodine deficiency, a WHO/ United Nations Children's Fund (UNICEF)/International Council for Control of Iodine Deficiency Disorders (ICCIDD) consultation in 1992 set the goal of maintaining a median UIC above $100 \mu \mathrm{g} / \mathrm{L}$ in school-age children and decreasing the population with a UIC less than $50 \mu \mathrm{g} / \mathrm{L}$ to less than $20 \%{ }^{1{ }^{11}}$ Since then, a country-by-country UIC assessment has been carried out on a world-wide scale, and data collected until 2011 covers $96.1 \%$ of the entire world population. ${ }^{12)}$

In 2013, Lee et al. ${ }^{13)}$ conducted a study of adolescents in several regions of Korea. These authors reported a median UIC of $438.8 \mu \mathrm{g} / \mathrm{L}$ among Korean adolescents and found Korea to be iodine-sufficient. However, to date, few investigations of the iodine status of Korean adolescents have been conducted at the national level.

Here, we analyzed the effects of regional, family, and socioeconomic factors on the body iodine status of Korean adolescents using data from the sixth Korea National Health and Nutrition Survey (KNHANES VI) covering the years 2013-2015.

\section{Materials and methods}

\section{Date source and participants}

This study used data from KNHANES VI (2013-2015), a 2-stage, stratified, cluster sampling survey with districts and households as the primary and secondary units, respectively, to extract a sample representative of the Korean population aged one year and over. KNHANES VI randomly selected 20 sample households from 192 districts that were investigated on a yearly basis and evaluated all members of the selected households. The investigation included a health questionnaire, health examination, and nutrition surveys. Data on the number of family members, type of generation, and household income were collected from one adult (aged 19 years or older) of each household based on the health questionnaire and health examination surveys, which were conducted at a mobile health examination center. The nutrition survey was conducted by visiting the households.

Data on thyroid diseases were collected from the health questionnaire survey. Thyroid test results included data on levels of thyroid stimulating hormone (TSH), free thyroxine (fT4), thyroid peroxidase antibody (TPO-Ab), and UIC. In this study, data from 1,034 adolescents aged 10-18 years who participated in the thyroid examination and their parents were analyzed.

\section{Biochemical analysis}

Blood samples were collected from the antecubital vein after a night of fasting. Samples were centrifuged for at least 30 minutes and transferred to the laboratory. Samples were analyzed within 24 hours of collection at the central lab in Seoul. Levels of TSH, fT4, and TPO-Ab were analyzed using electrochemiluminescence immunoassay. TSH was measured using the E-TSH kit (Roche Diagnostics, Mannheim, Germany) with normal reference values of $0.35-5.50 \mathrm{mIU} / \mathrm{L}$. Free thyroxine was measured using the E-Free T4 kit (Roche Diagnostics, Mannheim, Germany) with normal reference values of $0.89-1.76 \mathrm{ng} / \mathrm{mL}$. TPOAb level was measured using an E-Anti-TPO kit (Roche Diagnostics), and values were considered normal if they were lower than $34.0 \mathrm{IU} / \mathrm{mL}$. Single random urine samples were obtained from 1,034 adolescents aged $10-18$ years. UIC was measured by inductively coupled plasma mass spectrometry (ICP-MS, PerkinElmer, Waltham, MA, USA) using an iodine standard (Inorganic Venture, Christiansburg, VA, USA) and is reported as $\mu \mathrm{g} / \mathrm{L}$. The reported results met the guidelines regarding accuracy, general chemistry, special immunology, quality control, and quality assurance set forth by the College of American Pathologists.

\section{Definitions}

1) Categorization by UIC

Subjects were divided into 3 groups based on the School Age Children Epidemiological criteria established by the WHO.2) While UIC $<100 \mu \mathrm{g} / \mathrm{L}$ was defined as iodine deficiency, a UIC ranging from $100-299.9 \mu \mathrm{g} / \mathrm{L}$ was considered indicative of an adequate iodine level, while a UIC $\geq 300 \mu \mathrm{g} / \mathrm{L}$ marked iodine excess. In this study, UIC $\geq 3,000 \mu \mathrm{g} / \mathrm{L}$ was considered extreme iodine excess.

\section{2) Regional iodine status}

Iodine status was investigated in 7 metropolitan cities with a population size $\geq 1,000,000$, including Seoul and 9 provinces. Regions were divided into urban and rural regions. Small cities and large cities, including metropolitan cities, were classified as urban, while the remaining regions were classified as rural.

3) Family history of thyroid disease

A patient was deemed to have a family history of thyroid disease if at least one person in the family (parents, grandparents, 
or parent sibling) had been diagnosed with thyroid disease by a physician.

\section{4) Family structure}

A family consisting of parents living with their unmarried children was categorized as "both parents," while single mothers/ fathers living with their unmarried children, grandparents living with their unmarried grandchildren, or single grandparents living with their unmarried grandchildren were categorized as "other families."

\section{5) Average monthly household income}

Total household income was determined by adding all forms of income including salary, property income, pension, interest, and government subsidies. Average monthly household income was calculated based on total household income in the previous year. If the total household income in the previous year could not be calculated, the family was queried directly.

\section{6) Income quartile}

Income levels were divided into 4 quartiles (the first being the lowest and fourth being the highest), and the income range for each quartile was determined according to average monthly household income. Although there were differences in income levels between years, monthly income for the first to the fourth quartiles ranged from 0-761.2 thousand Korean won (KRW)
(714 US dollars [USD]), 761.2-1,574.9 thousand KRW (7141,477.4 USD), 1,575.9-2,687.7 thousand KRW (1,477.4-2,521.3 USD), and 2,687.7 and above thousand won (2,521.3 USD), respectively (basic exchange rate: $1 \mathrm{USD}=1.066$ thousand KRW as of December 29,2017).

7) Basic livelihood security recipients

Under the National Basic Living Security Act, basic living subsidies are provided to families in need of help to live independently. Eligible recipients are allowed to refer others who are qualified to receive these subsidies. In this study, basic livelihood security recipients were defined as those who were currently receiving these subsidies or had received them in the past.

\section{8) Obesity}

In accordance with the standard growth chart for children and adolescents (2007), obesity in either sex was defined as body mass index (BMI) in the 95th percentile or above or as BMI $\geq 25$ $\mathrm{kg} / \mathrm{m}^{2} \cdot{ }^{14)}$

\section{Statistical analysis}

To account for the complex survey design, design variables including primary sampling unit and strata were used in all statistical analyses. Sample weights were used to produce

Table 1. Regional distribution of iodine status among Korean adolescents

\begin{tabular}{|c|c|c|c|c|}
\hline & $\begin{array}{l}\text { lodine deficiency } \\
(\mathrm{UIC}<100 \mu \mathrm{g} / \mathrm{L})(\mathrm{n}=58)\end{array}$ & $\begin{array}{c}\text { Adequate iodine } \\
(\text { UIC 100-299.9 } \mathrm{g} / \mathrm{L})(\mathrm{n}=296)\end{array}$ & $\begin{array}{c}\text { lodine excess } \\
(\mathrm{UIC} \geq 300 \mu \mathrm{g} / \mathrm{L})(\mathrm{n}=680)\end{array}$ & $\begin{array}{l}\text { Extreme iodine excess } \\
(\mathrm{UIC} \geq 3,000 \mu \mathrm{g} / \mathrm{L})(\mathrm{n}=68)\end{array}$ \\
\hline \multicolumn{5}{|c|}{ Metropolitan cities and provinces in Korea } \\
\hline Seoul & $6.0 \% \pm 2.3 \%$ & $37.5 \% \pm 3.7 \%$ & $56.5 \% \pm 4.3 \%$ & $6.1 \% \pm 2.3 \%$ \\
\hline Busan & $9.5 \% \pm 4.3 \%$ & $34.8 \% \pm 7.3 \%$ & $55.7 \% \pm 9.8 \%$ & $0 \%$ \\
\hline Daegu & $7.9 \% \pm 3.9 \%$ & $38.3 \% \pm 9.4 \%$ & $53.9 \% \pm 9.9 \%$ & $5.1 \% \pm 3.5 \%$ \\
\hline Incheon & $10.2 \% \pm 5.1 \%$ & $16.6 \% \pm 5.6 \%$ & $73.2 \% \pm 6.8 \%$ & $11.2 \% \pm 5.1 \%$ \\
\hline Gwangju & $11.4 \% \pm 6.4 \%$ & $12.5 \% \pm 5.4 \%$ & $76.1 \% \pm 7.4 \%$ & $6.6 \% \pm 4.8 \%$ \\
\hline Daejeon & $1.2 \% \pm 1.2 \%$ & $29.0 \% \pm 9.6 \%$ & $69.8 \% \pm 9.9 \%$ & $2.9 \% \pm 2.1 \%$ \\
\hline Ulsan & $0 \%$ & $32.8 \% \pm 9.1 \%$ & $67.2 \% \pm 9.1 \%$ & $11.2 \% \pm 6.3 \%$ \\
\hline Gyeonggi-do & $5.5 \% \pm 1.7 \%$ & $23.6 \% \pm 3.0 \%$ & $70.9 \% \pm 3.3 \%$ & $8.2 \% \pm 1.9 \%$ \\
\hline Gangwon-do & $3.0 \% \pm 3.1 \%$ & $48.4 \% \pm 11.3 \%$ & $48.5 \% \pm 11.2 \%$ & $2.2 \% \pm 2.3 \%$ \\
\hline Chungcheongbuk-do & $8.3 \% \pm 5.5 \%$ & $25.0 \% \pm 9.3 \%$ & $66.7 \% \pm 8.0 \%$ & $2.8 \% \pm 2.9 \%$ \\
\hline Chungcheongnam-do & $13.0 \% \pm 7.7 \%$ & $36.7 \% \pm 8.3 \%$ & $50.3 \% \pm 8.0 \%$ & $4.8 \% \pm 2.7 \%$ \\
\hline Jeollabuk-do & $4.0 \% \pm 3.1 \%$ & $40.3 \% \pm 10.9 \%$ & $55.7 \% \pm 11.3 \%$ & $0 \%$ \\
\hline Jeollanam-do & $6.3 \% \pm 6.0 \%$ & $38.2 \% \pm 11.4 \%$ & $55.5 \% \pm 10.6 \%$ & $12.0 \pm 6.7 \%$ \\
\hline Gyeongsangbuk-do & $9.2 \pm 5.8 \%$ & $29.0 \% \pm 8.3 \%$ & $61.8 \% \pm 9.4 \%$ & $10.9 \% \pm 6.0 \%$ \\
\hline Gyeongsangnam-do & $9.2 \% \pm 4.4 \%$ & $22.0 \% \pm 6.1 \%$ & $68.8 \% \pm 7.9 \%$ & $3.6 \% \pm 2.5 \%$ \\
\hline Jeju-do & $5.0 \% \pm 4.3 \%$ & $26.0 \% \pm 11.2 \%$ & $68.9 \% \pm 12.0 \%$ & $17.4 \% \pm 12.7 \%$ \\
\hline Type of dwelling & $7.0 \% \pm 1.1 \%$ & $28.4 \% \pm 1.9 \%$ & $64.6 \% \pm 2.1 \%$ & $6.9 \% \pm 1.1 \%$ \\
\hline Urban area & $4.9 \% \pm 2.2 \%$ & $36.1 \% \pm 3.9 \%$ & $59.0 \% \pm 4.4 \%$ & $5.2 \% \pm 1.9 \%$ \\
\hline Rural area & $6.6 \% \pm 1.3 \%$ & $28.1 \% \pm 2.3 \%$ & $65.3 \% \pm 2.5 \%$ & $7.0 \% \pm 1.3 \%$ \\
\hline Small cities and towns & $6.7 \% \pm 1.5 \%$ & $32.2 \% \pm 2.5 \%$ & $61.1 \% \pm 2.9 \%$ & $5.9 \% \pm 1.4 \%$ \\
\hline Above metropolitan cities & $6.6 \% \pm 1.0 \%$ & $29.8 \% \pm 1.7 \%$ & $63.6 \% \pm 1.9 \%$ & $6.6 \% \pm 0.9 \%$ \\
\hline Total & $6.0 \% \pm 2.3 \%$ & $37.5 \% \pm 3.7 \%$ & $56.5 \% \pm 4.3 \%$ & $6.1 \% \pm 2.3 \%$ \\
\hline
\end{tabular}

Values are presented as weighted percent \pm standard error.

UIC, urinary iodine concentration.

*lodine excess included extreme iodine excess. 
unbiased national estimates. All statistical analyses were performed using IBM SPSS Statistics ver. 23.0 (IBM Co., Armonk, NY, USA). Results are expressed as weighted mean \pm standard error $(\mathrm{SE})$ or weighted percent \pm SE. Among the participants' general characteristics, socio-economic status and thyroid function as continuous variables were compared using complex sample general linear models, while categorical variables were compared using logistic regression. Multiple logistic regression analysis was performed to determine odds ratio and 95\% confidence interval for the association between iodine status and socio-economic variables. $P$-values $<0.05$ were considered statistically significant.

\section{Results}

\section{1. lodine status in Korean adolescents}

Mean UIC in Korean adolescents was $963.5 \pm 55.7 \mu \mathrm{g} / \mathrm{L}$. While $6.6 \% \pm 1.0 \%$ of subjects had iodine deficiency with a mean UIC of $67.7 \pm 3.5 \mu \mathrm{g} / \mathrm{L}, 29.8 \% \pm 1.7 \%$ had adequate levels of iodine with a mean UIC of $203.5 \pm 3.7 \mu \mathrm{g} / \mathrm{L}$, and $63.9 \% \pm 1.9 \%$ had excess iodine levels with a mean UIC of $1,412.8 \pm 78.4 \mu \mathrm{g} / \mathrm{L}$. Extreme iodine excess was seen in $6.6 \% \pm 0.9 \%$ of participants with a mean UIC of 5,575.1 $\pm 343.1 \mu \mathrm{g} / \mathrm{L}$ (Tables 1,2 ).

\section{Regional iodine status}

Table 1 shows the regional iodine status of Korean adolescents. Although iodine excess dominated across the country, a high incidence of iodine deficiency was observed in some regions. While Chungcheongnam-do had the highest incidence of iodine deficiency (13.0\% $\pm 7.7 \%)$, that in in Gwangju and Incheon also exceeded 10\%. While the highest incidence of extreme iodine excess was seen in Jeju-do (17.4\% $\pm 12.7 \%)$, it exceeded $10 \%$ in Jeollanam-do, Ulsan, Incheon, and Gyeongsangbuk-do.

\section{Markers associated with thyroid function and iodine status}

The fT4 values were higher in the adequate iodine group than the other two groups, but all fT4 values were within the normal range. Similarly, although iodine-deficient and excess groups had higher TSH levels than the adequate iodine group, they were all within the normal ranges. No differences in TPO-Ab level were found among groups (Table 2).

\section{UIC and thyroid function of the parents and iodine status}

Maternal UIC values in the iodine deficient, adequate, and excess groups were $273.63 \pm 49.59 \mu \mathrm{g} / \mathrm{L}, 522.45 \pm 71.48 \mu \mathrm{g} / \mathrm{L}$, and $923.88 \pm 122.57 \mu \mathrm{g} / \mathrm{L}$, respectively. Paternal UIC values in the iodine deficient, adequate, and excess groups were $232.40 \pm 44.20$ $\mu \mathrm{g} / \mathrm{L}, 467.69 \pm 82.35 \mu \mathrm{g} / \mathrm{L}$, and $780.07 \pm 88.60 \mu \mathrm{g} / \mathrm{L}$, respectively. Both maternal and paternal UIC increased as the UIC of the offspring increased. However, no differences in maternal or paternal levels of TSH, free-T4, or TPO-Ab were observed among the groups (Table 2).

\section{Socioeconomic conditions and iodine status}

Table 3 summarizes the socio-economic characteristics of Korean adolescents based on iodine status.

The average monthly household income was lowest in the iodine-deficient group $(3,365.9 \pm 331.7$ thousand KRW

Table 2. Indicators of thyroid function based on iodine status in Korean adolescents and their families

\begin{tabular}{|c|c|c|c|c|}
\hline Variable & $\begin{array}{c}\text { lodine deficiency } \\
(\mathrm{UIC}<100 \mu \mathrm{g} / \mathrm{L})(\mathrm{n}=58)\end{array}$ & $\begin{array}{c}\text { Adequate iodine } \\
(\text { UIC } 100-299.9 \mu \mathrm{g} / \mathrm{L})(\mathrm{n}=296)\end{array}$ & $\begin{array}{c}\text { lodine excess } \\
(\mathrm{UIC} \geq 300 \mu \mathrm{g} / \mathrm{L})(\mathrm{n}=680)\end{array}$ & $P$-value \\
\hline $\mathrm{UIC}(\mu / \mathrm{L})$ & $67.7 \pm 3.5$ & $203.5 \pm 3.7$ & $1412.8 \pm 78.4$ & 0.000 \\
\hline Free T4 (ng/dL) & $1.26 \pm 0.03$ & $1.37 \pm 0.03$ & $1.28 \pm 0.01$ & 0.035 \\
\hline $\mathrm{TSH}(\mu \mathrm{IU} / \mathrm{mL})$ & $2.95 \pm 0.21$ & $2.59 \pm 0.11$ & $2.95 \pm 0.08$ & 0.016 \\
\hline TPO-Ab (IU/mL) & $7.98 \pm 0.65$ & $20.71 \pm 9.71$ & $11.25 \pm 1.45$ & 0.050 \\
\hline Maternal UIC ( $\mu / L)$ & $273.63 \pm 49.59$ & $522.45 \pm 71.48$ & $923.88 \pm 122.57$ & 0.000 \\
\hline Maternal free T4 (ng/dL) & $1.08 \pm 0.05$ & $1.22 \pm 0.04$ & $1.17 \pm 0.01$ & 0.109 \\
\hline Maternal TSH $(\mu \mathrm{IU} / \mathrm{mL})$ & $2.33 \pm 0.41$ & $2.87 \pm 0.25$ & $3.09 \pm 0.24$ & 0.280 \\
\hline Maternal TPO-Ab (IU/mL) & $31.52 \pm 13.79$ & $22.64 \pm 8.22$ & $56.96 \pm 22.23$ & 0.336 \\
\hline Paternal UIC ( $\mu / L)$ & $232.40 \pm 44.20$ & $467.69 \pm 82.35$ & $780.07 \pm 88.60$ & 0.000 \\
\hline Paternal free T4 (ng/dL) & $1.35 \pm 0.06$ & $1.27 \pm 0.02$ & $1.25 \pm 0.02$ & 0.229 \\
\hline Paternal TSH $(\mu \mid \mathrm{U} / \mathrm{mL})$ & $3.01 \pm 0.47$ & $2.40 \pm 0.18$ & $2.70 \pm 0.17$ & 0.276 \\
\hline Paternal TPO-Ab (IU/mL) & $7.82 \pm 1.26$ & $16.40 \pm 6.83$ & $34.45 \pm 16.95$ & 0.141 \\
\hline \multicolumn{5}{|c|}{ Family history of thyroid disease } \\
\hline Yes & $7.8 \% \pm 3.1 \%$ & $25.0 \% \pm 4.6 \%$ & $67.2 \% \pm 5.3 \%$ & 0.567 \\
\hline No & $6.5 \% \pm 1.0 \%$ & $30.3 \% \pm 1.8 \%$ & $63.2 \% \pm 2.0 \%$ & \\
\hline
\end{tabular}

Values are presented as mean \pm standard error or weighted percent \pm standard error.

UIC, urinary iodine concentration; free T4, free thyroxine; TSH, thyroid stimulating hormone; TPO-Ab, thyroid peroxidase antibody. 
$[3,157.5 \pm 311.2$ USD $])$ compared to the adequate iodine group $(4,220.4 \pm 196.7$ thousand KRW [3,959.1 \pm 184.5 USD] $)$ and excess iodine group $(4,434.3 \pm 131.5$ thousand KRW $[4,160 \pm 123.4 \mathrm{USD}])$. No difference in UIC was found based on income quartile, basic livelihood security status, or family structure.

\section{Multiple logistic regression analysis of risk factors for iodine deficiency and extreme excess}

The risk of iodine deficiency was about 9 times higher among girls than boys. It decreased by $28.4 \%$ when average total household income increased by 1 million KRW (Table 4). The risk of extreme iodine excess increased by 3.5\% for every 100 $\mu \mathrm{g} / \mathrm{L}$ increase in maternal UIC (Table 5).

\section{Discussion}

In this study, we investigated the iodine status of Korean adolescents and their parents using nation-wide data.

After salt iodization was introduced in the United States and Switzerland in 1920, the World Health Assembly endorsed Universal Salt Iodization (USI) and recommended including at least $20-40 \mathrm{mg}$ of iodine per $1 \mathrm{~kg}$ of salt to satisfy iodine requirements. ${ }^{15)}$ Since the adoption of salt iodization, there have been consistent improvements in nutritional iodine in Africa, Switzerland, Europe, the eastern Mediterranean, Southeast Asia, and the western Pacific region. ${ }^{16)}$ Level of iodine intake and iodine sources differ between countries and regions. While low iodine intake has been reported in most European countries and the United States, high iodine intake has been reported in Korea and Japan. ${ }^{17)}$ In countries where an iodized

Table 3. General and socio-economic characteristics of Korean adolescents based on iodine status

\begin{tabular}{|c|c|c|c|c|}
\hline Variable & $\begin{array}{l}\text { lodine deficiency } \\
(\mathrm{UIC}<100 \mu \mathrm{g} / \mathrm{L})(\mathrm{n}=58)\end{array}$ & $\begin{array}{l}\text { Adequate iodine } \\
\text { (UIC 100-299.9 } \mathrm{gg} / \mathrm{L})(\mathrm{n}=296)\end{array}$ & $\begin{array}{c}\text { lodine excess } \\
(\mathrm{UIC} \geq 300 \mu \mathrm{g} / \mathrm{L})(\mathrm{n}=680)\end{array}$ & $P$-value \\
\hline Age (yr) & $14.28 \pm 0.37$ & $14.67 \pm 0.17$ & $13.91 \pm 0.11$ & 0.001 \\
\hline \multicolumn{5}{|l|}{ Sex } \\
\hline Male & $5.2 \% \pm 1.1 \%$ & $31.3 \% \pm 2.3 \%$ & $63.5 \% \pm 2.4 \%$ & 0.147 \\
\hline Female & $8.6 \% \pm 1.7 \%$ & $27.7 \% \pm 2.3 \%$ & $63.7 \% \pm 2.7 \%$ & \\
\hline \multicolumn{5}{|l|}{ Obesity } \\
\hline Yes & $7.9 \% \pm 4.1 \%$ & $32.0 \% \pm 5.3 \%$ & $60.1 \% \pm 6.2 \%$ & 0.833 \\
\hline No & $6.5 \% \pm 1.0 \%$ & $29.5 \% \pm 1.8 \%$ & $64.0 \% \pm 2.0 \%$ & \\
\hline Average monthly income and expenditure (1,000 KRW) & $3,365.9 \pm 331.7$ & $4,220.4 \pm 196.7$ & $4,424.3 \pm 131.5$ & 0.009 \\
\hline Income quartile & & & & 0.120 \\
\hline First (lowest) & $12.9 \% \pm 4.5 \%$ & $34.7 \% \pm 5.5 \%$ & $52.4 \% \pm 5.6 \%$ & \\
\hline Second & $8.2 \% \pm 2.1 \%$ & $29.4 \% \pm 3.5 \%$ & $62.3 \% \pm 3.6 \%$ & \\
\hline Third & $5.9 \% \pm 1.4 \%$ & $30.5 \% \pm 2.7 \%$ & $63.5 \% \pm 3.1 \%$ & \\
\hline Fourth (highest) & $3.8 \% \pm 1.4 \%$ & $27.3 \% \pm 3.1 \%$ & $68.9 \% \pm 3.2 \%$ & \\
\hline \multicolumn{5}{|l|}{ Basic livelihood security recipients } \\
\hline Yes & $7.2 \% \pm 3.1 \%$ & $31.7 \pm 5.8 \%$ & $61.1 \% \pm 5.9 \%$ & \\
\hline No & $6.5 \% \pm 1.0 \%$ & $29.5 \pm 1.8 \%$ & $63.9 \% \pm 2.0 \%$ & 0.900 \\
\hline Family structure & & & & 0.504 \\
\hline Both parents & $6.0 \% \pm 1.1 \%$ & $29.7 \% \pm 2.0 \%$ & $64.3 \% \pm 2.2 \%$ & \\
\hline Other families & $7.6 \% \pm 2.4 \%$ & $27.7 \% \pm 4.1 \%$ & $64.7 \% \pm 4.4 \%$ & \\
\hline
\end{tabular}

Values are presented as mean \pm standard error or weighted percent \pm standard error.

UIC, urinary iodine concentration; KRW, Korean won.

Table 4. Multiple logistic regression analysis of risk factors associated with iodine deficiency

\begin{tabular}{lccc}
\hline Variable & Odds ratio & $95 \% \mathrm{Cl}$ & $P$-value \\
\hline Female sex & 9.076 & $1.775-46.400$ & 0.009 \\
Urban & 0.357 & $0.460-2.798$ & 0.322 \\
Obesity & 3.574 & $0.339-37.735$ & 0.285 \\
Age $(y r)$ & 1.033 & $0.810-1.319$ & 0.789 \\
Paternal UIC $(100 \mu / L)$ & 0.712 & $0.473-1.074$ & 0.104 \\
Maternal UIC $(100 \mu / L)$ & 0.825 & $0.587-1.159$ & 0.263 \\
Average monthly income and & 0.716 & $0.552-0.929$ & 0.013
\end{tabular}

$\mathrm{Cl}$, confidence interval; UIC, urinary iodine concentration; KRW,

Korean won.
Table 5. Multiple logistic regression analysis of risk factors associated with extreme iodine excess

\begin{tabular}{|c|c|c|c|}
\hline Variable & Odds ratio & $95 \% \mathrm{Cl}$ & $P$-value \\
\hline Female & 0.806 & $0.301-2.154$ & 0.663 \\
\hline Urban & 1.315 & $0.226-7.652$ & 0.757 \\
\hline Obesity & 2.185 & $0.436-10.944$ & 0.336 \\
\hline Age (yr) & 0.782 & $0.590-1.037$ & 0.086 \\
\hline Paternal UIC (100 $\mu / L)$ & 1.006 & $0.963-1.051$ & 0.781 \\
\hline Maternal UIC (100 $\mu / L)$ & 1.035 & $1.001-1.070$ & 0.045 \\
\hline $\begin{array}{l}\text { Average monthly income and } \\
\text { expenditure }(1,000,000 \mathrm{KRW})\end{array}$ & 1.146 & $0.991-1.325$ & 0.065 \\
\hline
\end{tabular}

$\mathrm{Cl}$, confidence interval; UIC, urinary iodine concentration; KRW, Korean won. 
salt program has been implemented, iodized salt is the most important source of iodine. ${ }^{18)}$ In the United States, Canada, and industrialized European countries, dairy products such as milk, eggs, cereals, iodized salt, and bakery products are major sources of iodine. ${ }^{19)}$ For Koreans, the major sources of dietary iodine are seaweed $(65.6 \%)$, salted vegetables (18.0\%), fish $(4.8 \%)$, milk and dairy products (2.9\%), and grains $(2.5 \%){ }^{20)} \mathrm{In}$ Korea, the daily recommended iodine intake was set to $90 \mu \mathrm{g} /$ day for preschool children aged $0-5$ years, $120 \mu \mathrm{g} /$ day for school children aged 6-12 years, and $150 \mu \mathrm{g} /$ day for adolescents (above 12 years) and adults, based on data from the WHO/UNICEF/ ICCIDD. ${ }^{2}$ Han et al. ${ }^{20)}$ reported that the average daily iodine intake of Korean adults was $215.5-726.5 \mu \mathrm{g} /$ day, which exceeds the recommended amount. In a study on Korean children and adolescents, some regions of Korea were found to be iodinesufficient. ${ }^{13)}$ In the present study on Korean adolescents aged $10-18$ years from all regions, the mean UIC was $963.5 \pm 55.7 \mu \mathrm{g} /$ $\mathrm{L}$, indicative of high levels of body iodine.

Geography is believed to be a major factor responsible for iodine excess because seafood and seaweeds are easily available and abundant in coastal Korea. In addition, economic development and industrial development are other factors that affect nutritional status. In this study, iodine levels were analyzed in each administrative district to determine the iodine status and characteristics of each region. Jeju-do, Jeollanam-do, and Ulsan were identified as regions with excess iodine levels, with more than $10 \%$ of individuals in these regions having a UIC $\geq 3,000 \mu \mathrm{g} / \mathrm{L}$. In Chungcheongnam-do, Gwangju, and Incheon, the incidence of iodine deficiency was relatively high, with over $10 \%$ of the region's population having a UIC $\leq 100 \mu \mathrm{g} / \mathrm{L}$. Iodine excess and iodine deficiency were simultaneously observed in Gwangju and Incheon. Although Korea is overall a country with excess iodine, iodine status varied among regions. Jeju-do is the largest island in Korea, so its geographical characteristics appear to be the major cause for the excess iodine seen there, though further investigation of the socioeconomic factors, cooking methods, and preferred food is needed. Costante et al. ${ }^{21)}$ reported higher goiter prevalence and insufficient iodine intake in inland mountain areas compared to coastal areas. In a study by Aghini-Lombardi et al. ${ }^{22}$ on adolescents aged 11-14 years from iodine-deficient regions, higher iodine intake was found in urban areas with high population densities, coastal mountainous/hilly areas, and lowland compared to areas with low population densities and inland mountainous/hilly areas. However, considering that Korea has a high population density and a high proportion of cities, ${ }^{23)}$ and iodine is present in various types of food, socioeconomic factors, in addition to geographical factors, may play an important role in determining iodine status. Additionally, according to an analysis of trends in iodine intake of Korean adults from 1998 to 2014, overall consumption of iodine has decreased, although the cause is not clear. ${ }^{24)}$ With the overall decrease in consumption of iodine by Korean adults, iodine deficiency in adolescents is not unexpected. We believe that education is necessary to ensure that Korean adolescents eat a balanced diet; parents, adolescents, and school nutritionists should be educated on proper iodine intake.

In this study, the iodine statuses of adolescents and their parents appear to be associated. In the extreme iodine excess group with UIC $\geq 3,000 \mu \mathrm{g} / \mathrm{L}$, maternal iodine status was associated with child's iodine status. However, additional research is needed to understand this intrafamily association of iodine status.

In the iodine-deficient group of Korean adolescents, iodine deficiency was (1) more common among girls than boys and (2) inversely related to an increase in average total monthly household income. These results support the previous finding that iodine intake among Koreans increases as income and education levels increase. ${ }^{20)}$ An iodine intake study of Korean adults reported that female participants ingested less iodine than male participants. ${ }^{24)}$ No studies have analyzed sex differences in iodine intake in Korean adolescents, but in British youth, iodine intake in female adolescents was lower than that in male adolescents. ${ }^{25)}$ Therefore, the higher risk of iodine deficiency in female individuals may be due to sex-related differences in diet.

A study by Knudsen et al. ${ }^{26)}$ of adults showed a decrease in incidence of goiter as education level increased. In another study on elderly subjects aged 60 years or older, income and employment status were associated with the incidence of subclinical thyroid dysfunction, suggesting that thyroid diseases might be associated with socioeconomic factors. ${ }^{27)}$

In industrialized countries that have been classified as areas with adequate or excessive iodine intake, such as England and Ireland, iodine deficiency has reemerged in certain age groups due to changes in eating habits. ${ }^{28)}$ Increased prevalence of western diets in Korea may also contribute to iodine deficiency in the younger population.

Although UIC was statistically associated with levels of TSH and fT4 in the present study, no association was found between iodine status and incidence of thyroid dysfunction. Nevertheless, in a study performed by Kang et al. ${ }^{29)}$ on children and adolescents, iodine excess was found to be associated with subclinical hypothyroidism. Iodine excess has also been reported to be associated with iodine-induced thyroid dysfunction and autoimmune thyroid diseases. ${ }^{30)}$ This suggests the possibility that iodine status, up to a certain level, will have less impact on thyroid dysfunction in adolescence than in adulthood. Therefore, it may be necessary to assess long-term thyroid function according to iodine status.

This study had some limitations. First, this study was based on KHANES VI, which is a cross-sectional survey; therefore, causality between UIC and thyroid disease within families could not be assessed. Second, international organizations such as WHO and UNICEF have used single random sampling UIC to compare public health data among countries, so we used single random sampling UIC in this study; however, UIC determined from a single random urine sample is inevitably affected by daily variations and dehydration. Therefore, additional data analysis using multiple spot UIC, 24-hour UIC, and urine iodine creatinine ratio, among other parameters, is required to improve 
reliability. Finally, although the iodine status of adolescents seems to be associated with the eating habits of their families, we did not evaluate dietary lifestyle factors of families and therefore could not clearly analyze the association between these two. Therefore, additional research on the eating habits and iodine status of Korean adolescents is needed.

In conclusion, there are regional differences in iodine status among Korean adolescents, and levels are affected by the eating habits of their families and other socioeconomic factors. Continuous monitoring of iodine status is therefore necessary.

\section{Ethical statement}

All participants in KNHANES VI provided informed consent. The protocol for KNHANES VI was approved by the In $\neg$ stitutional Review Board of the Korea Centers for Disease Control and Prevention (2013-07CON-03-4C, 2013-12EXP03-5C). Our study was approved by the Institutional Review Board of Dong-A University Hospital (DAUHIRBEXP-18-023).

\section{Conflict of interest}

No potential conflict of interest relevant to this article was reported.

\section{References}

1. Caulfield LE, Richard SA, Rivera JA, Musgrove P, Black RE. Stunting, wasting, and micronutrient deficiency disorders. In: Jamison DT, Breman JG, Measham AR, Alleyne G, Claeson M, Evans DB, et al., editors. Disease control priorities in developing countries. 2nd ed. New York: Oxford University Press, 2006:551-68.

2. International Council for Control of Iodine Deficiency Disorders; UNICEF; World Health Organization. Assessment of iodine deficiency disorders and monitoring their elimination. 3rd ed. Geneva (Switzerland): World Health Organization, 2007.

3. Vanderpas J. Nutritional epidemiology and thyroid hormone metabolism. Annu Rev Nutr 2006;26:293-322.

4. Trumbo P, Yates AA, Schlicker S, Poos M. Dietary reference intakes: vitamin A, vitamin $\mathrm{K}$, arsenic, boron, chromium, copper, iodine, iron, manganese, molybdenum, nickel, silicon, vanadium, and zinc. J Am Diet Assoc 2001;101:294301.

5. Wolff J, Chaikoff IL, Goldberg, Meier JR. The temporary nature of the inhibitory action of excess iodide on organic iodine synthesis in the normal thyroid. Endocrinology 1949;45:504-13.

6. Sang Z, Chen W, Shen J, Tan L, Zhao N, Liu H, et al. Longterm exposure to excessive iodine from water is associated with thyroid dysfunction in children. J Nutr 2013;143:203843.
7. Zimmermann M, Saad A, Hess S, Torresani T, Chaouki N. Thyroid ultrasound compared with World Health Organization 1960 and 1994 palpation criteria for determination of goiter prevalence in regions of mild and severe iodine deficiency. Eur J Endocrinol 2000;143:727-31.

8. Zimmermann MB, Andersson M. Assessment of iodine nutrition in populations: past, present, and future. Nutr Rev 2012;70:553-70.

9. Nath SK, Moinier B, Thuillier F, Rongier M, Desjeux JF. Urinary excretion of iodide and fluoride from supplemented food grade salt. Int J Vitam Nutr Res 1992; 62:66-72.

10. Jahreis G, Hausmann W, Kiessling G, Franke K, Leiterer M. Bioavailability of iodine from normal diets rich in dairy products--results of balance studies in women. Exp Clin Endocrinol Diabetes 2001;109:163-7.

11. Organización Mundial de la Salud (Ginebra). Indicators for assessing iodine deficiency disorders and their control through salt iodization. Geneva (Switzerland): World Health Organization, 1994.

12. Andersson M, Karumbunathan V, Zimmermann MB. Global iodine status in 2011 and trends over the past decade. J Nutr 2012;142:744-50.

13. Lee J, Kim JH, Lee SY, Lee JH. Iodine status in Korean preschool children as determined by urinary iodine excretion. Eur J Nutr 2014;53:683-8.

14. Moon JS, Lee SY, Nam CM, Choi JM, Choe BK, Seo JW, et al. 2007 Korean national growth charts: review of developmental process and an outlook. Korean J Pediatr 2008;51:1-25.

15. World Health Organization. Regional Office for Europe. Nutrition Unit. Recommended iodine levels in salt and guidelines for monitoring their adequacy and effectiveness. Geneva (Switzerland): World Health Organization, 1996.

16. United Nations Children's Fund (UNICEF). The state of the world's children 2012: children in an urban world. New York: UNCEF, 2012.

17. Ristić-Medić D, Dullemeijer C, Tepsić J, Petrović-Oggiano G, Popović T, Arsić A, et al. Systematic review using metaanalyses to estimate dose-response relationships between iodine intake and biomarkers of iodine status in different population groups. Nutr Rev 2014;72:143-61.

18. Charlton K, Skeaff S. Iodine fortification: why, when, what, how, and who? Curr Opin Clin Nutr Metab Care 2011;14:618-24.

19. Expert Group of Vitamins and Minerals. Safe upper levels for vitamins and minerals. London: Food Standards Agency; 2003.

20. Han MR, Ju DL, Park YJ, Paik HY, Song Y. An iodine database for common Korean foods and the association between iodine intake and thyroid disease in Korean adults. Int J Thyroidol 2015;8:170-82.

21. Costante G, Grasso L, Schifino E, Marasco MF, Crocetti $\mathrm{U}$, Capula C, et al. Iodine deficiency in Calabria: characterization of endemic goiter and analysis of different 
indicators of iodine status region-wide. J Endocrinol Invest 2002;25:201-7.

22. Aghini-Lombardi F, Vitti P, Antonangeli L, Fiore E, Piaggi P, Pallara A, et al. The size of the community rather than its geographical location better defines the risk of iodine deficiency: results of an extensive survey in Southern Italy. J Endocrinol Invest 2013;36:282-6.

23. United Nations, Department of Economic and Social Affairs. Population Division. World urbanization prospects: the 2014 revision. New York: UN, 2015

24. Ko YM, Kwon YS, Park YK. An iodine database establishment and iodine intake in Korean adults: Based on the 1998 2014 Korea National Health and Nutrition Examination Survey. J Nutr Health 2017;50:624-44.

25. Glynn L, Emmett P, Rogers I; ALSPAC Study Team. Food and nutrient intakes of a population sample of 7 -year-old children in the south-west of England in 1999/2000 - what difference does gender make? J Hum Nutr Diet 2005;18:719.
26. Knudsen N, Bulow I, Laurberg P, Ovesen L, Perrild H, Jorgensen T. Low socio-economic status and familial occurrence of goitre are associated with a high prevalence of goitre. Eur J Epidemiol 2003;18:175-81.

27. Wilson S, Parle JV, Roberts LM, Roalfe AK, Hobbs FD, Clark P, et al. Prevalence of subclinical thyroid dysfunction and its relation to socioeconomic deprivation in the elderly: A community-based cross-sectional survey. J Clin Endocrinol Metab 2006;91:4809-16.

28. Li M, Eastman CJ. The changing epidemiology of iodine deficiency. Nat Rev Endocrinol 2012;8:434-40.

29. Kang MJ, Hwang IT, Chung HR. Excessive iodine intake and subclinical hypothyroidism in children and adolescents aged 6-19 years: results of the sixth Korean national health and nutrition examination survey, 2013-2015. Thyroid 2018;28:773-9

30. Teng W, Shan Z, Teng X, Guan H, Li Y, Teng D, et al. Effect of iodine intake on thyroid diseases in china. $\mathrm{N}$ Engl J Med 2006;354:2783-93. 